DOI 10.15393/j9.art.2014.736

Евгений Михайлович Неёлов

доктор филологических наук, профессор кафедры русской литературы и журналистики, Петрозаводский государственный университет (Петрозаводск, Российская Федерация)

\title{
СКАЗКА А. ПУШКИНА «О ПОПЕ И О РАБОТНИКЕ ЕГО БА ДДЕ»
}

Аннотация. «Сказка о попе и о работнике его Балде» кажется на первый взгляд самой простой из всех пушкинских сказок. Однако это особая простота, простота сложности. В сказке существуют разные, не всегда сразу заметные, уровни содержания. Традиционная трактовка рассматривала "Сказку о Балде» как острую социально-политическую сатиру, другой подход связан с особенностями поэтики фольклорной сказки и её литературной трансформации, связанной с трудностями совмещения фольклорно-сказочной функции персонажа и характера литературно-сказочного героя. Оба эти подхода вызывают ряд вопросов, главный из которых - за что всё-таки наказали попа?

Третья интерпретация, рассматривающая пушкинскую сказку в христианском контексте, позволяет ответить на эти вопросы, позволяет раскрыть глубинные коннотации пушкинского замысла, давая возможность по-новому прокомментировать строки, обычно пропускаемые исследователями, акцентирующими внимание только на поверхностых смысловых уровнях текста.

Ключевые слова: фольклорная сказка, литературная сказка, священник, Балда, бес

$\mathrm{P}$ азмышляя над художественной природой сказочного мира, созданного А. Пушкиным, В. Непомнящий заметил: «Сказки Пушкина - тайна, особенно для того, кто берётся их анализировать. Они ошеломляют сочетанием бесшабашного, азартного простодушия, классической строгости и глубокой, почти скорбной, серьёзности и ускользают, как ускользает горизонт. Их дразнящая простота повергает порой в отчаяние» [7, 3]. Единственным исключением, на первый взгляд, является «Сказка о попе и о работнике его Балде», которая никуда не «ускользает», ибо в ней всё «ясно». Жадный поп, встретивший на свою беду Балду, получил по заслугам. «Ясность содержания» сказки связана с тем, что она читается как сатира, точнее, как социальная сатира. М. Азадовский в своё время сочувственно цитировал слова М. Горького о том, что в своих сказках «насмешливое, отри- 
цательное отношение народа к попам и царям Пушкин не скрыл, не затушевал, а, напротив, оттенил ещё более резко», - и подчёркивал: «В этом сущность художественного метода сказок» $[1,54]$. Сказку же о Балде М. Азадовский называл «социально-острой, сатирической» $[1,58]$. Эта точка зрения, подкреплённая авторитетом М. Горького и М. Азадовского, в советское время стала общераспространённой. В 1959 году в интересной, глубокой монографии, в известном смысле подводящей итоги изучения народной сказки в творчестве русских писателей первой половины XIX века, в полном соответствии с устоявшимся мнением, И. Лупанова писала: “"Сказка о попе и о работнике его Балде...” сразу же обращает на себя внимание социальным характером самого конфликта, положенного в её основу. <...> Объект сатирического осмеяния этих (народных, бытовых. - E. Н.) сказокжадный, корыстолюбивый поп-эксплуататор, все помыслы которого направлены на то, чтоб как можно дешевле заплатить за рабочую силу и как можно больше из неё выжать. Именно таков "поп-толоконный лоб" у Пушкина. Ему нужен работник, который был бы одновременно "повар, конюх и плотник" и обошёлся вместе с тем как можно дешевле» $[2,159-160]$.

Примечательно, что именно из такого сатирически-социального «ясного» смысла «Сказки о Балде» исходят и противники пушкинского сюжета (особенно в церковной среде), существующие и сегодня. И. Лупанова цитирует статью священника К.Д. Думитракова «Сказки и нравственно-воспитательное их значение», опубликованную в 1873 году в «Руководстве для сельских пастырей»: «...пресловутая сказка знаменитого Пушкина <...> не только не учит ничему доброму, но даже не пленяет нас своим содержанием» и считает слова священника подтверждением остро-сатирического смысла пушкинского текста $[2,164]$.

Современные исследователи в меньшей степени говорят о сатирическом смысле сказки, но указывают на её театральность [4, 179-180], «весёлость», «юмор» [8, 243]. В. Сдобнов называет демонологию «Сказки о попе и о работнике его Балде» «шутливой» $[11,238]$. 
Современный писатель замечает: «А большинство представлений о некой религиозной дремучести является общественным мифом, использующим в качестве персонажа этакого гротескного (подчёркнуто мной. $-E$. H.) попа типа героя пушкинской сказки о попе и о работнике его Балде»'. В этом, конечно же, есть свой резон. Такое восприятие составляет самый первый, лежащий на поверхности, видимый, так сказать, невооружённым взглядом уровень содержания сказки Пушкина. Именно этот уровень делает содержание безусловно «ясным».

Мы разделяем мнение В. Непомнящего: «До последнего времени изучение пушкинских сказок сводилось к узкоспециальным фольклористическим аспектам (источники, язык, стиль и пр.); в этом своеобразно и невольно отражалась традиция недооценки серьёзного и самостоятельного значения этой сферы пушкинского творчества <необходимо. - E. H.> рассмотреть сказку как непосредственно опирающуюся на фольклор неотъемлемую и важнейшую часть художественного мира Пушкина» $[8,188]$.

В своё время В. Розанов справедливо сказал: «Пушкин это покой, ясность и уравновешенность» $[10,372]$. Однако «ясность» Розанова не только не отменяет слова В. Непомнящего, которые я цитировал в начале статьи, но прямо противоречит плоской, однозначной, без усилий сразу «понятной» якобы «ясности» пушкинской сказки. «Ясность» Пушкина у Розанова не означает простоту (которая хуже воровства), она измеряется глубиной погружения в пучины художественного мира поэта, пучины, вода в которых столь прозрачна, что поверхностный читатель порой и не замечает их глубины, наивно считая, что дно совсем рядом. Такое восприятие сказочного смысла не противоречит вышесказанному, тем более не снимает его интерпретацию как остросатирическую.

Второй, более глубокий, нежели «ясный» первый, уровень смысла пушкинской сказки становится заметным тогда, когда мы начинаем читать сказку Пушкина именно как сказку, то есть воспринимать сказочную «ложь» (а не «намёки») «всерьёз» и не присваивать событиям аллегорического или 
иного иносказательного значения, порой весьма произвольного и субъективного (при этом, как знают специалисты, исчезает сама фантастика), а рассматриваем сами эти сказочные события, ничего не пропуская и не добавляя.

И тогда возникают вопросы. Почему «преступление» попа и его «наказание» так несоразмерны? В самом деле:

Пошёл поп по базару

Поискать кой-какого товару... (351) ${ }^{2}$

Причём поп хотел поискать подешевле, но разве это преступление? А что, читатель, придя на базар, непременно хочет купить подороже? И вот за это при «помощи» Балды поп теряет разум. Это страшное наказание в мире Пушкина, порой оно хуже смерти: стоит вспомнить его стихотворение «Не дай мне Бог сойти с ума», звучащее то ли как языческое заклинание, то ли как молитва.

«Неужели вас не коробит жестокость этого (сказочного. E. H.) весёлого финала?» - спрашивал у читателей ещё в 1972 году В. Непомнящий, повторяя этот вопрос в монографии «Поэзия и судьба» $[8,214]$ и сам же отвечал на него: «Нет, веселье не безоблачно и попа жалко. И наказание кажется неоправданно жестоким» $[6,148]$.

Это тем более так, потому что в финале поп предстаёт в виде не священника, а просто старого человека:

А с третьего щелчка

Вышибло ум у старика. (214)

«Поп» стал «стариком». Это выглядит странным, даже с педагогической точки зрения, которая всегда ищет в сказках прямо выраженную мораль и исходит из теории подражания, по которой читатель стремится стать таким, как герой, подражать ему. Представьте себе картину: молодой, сильный («работает за семерых»), с хорошим аппетитом («ест за троих»), весёлый парень бьёт старика, безнадёжно калеча его. Этому надо «подражать»? А мы думаем, почему молодёжь часто не уважает старость, не уступает старикам место в автобусе? Кто виноват? Ну, конечно же, Пушкин! Он научил. 
А если говорить серьёзно, то дело, по всей видимости, заключается в следующем. Как давно известно в фольклористике, в народной сказке нет характеров героев, но зато решающее значение имеют их функции. В. Пропп писал: «Под функцией понимается поступок действующего лица, определённый с точки зрения его значимости для хода действия. <...> Постоянными устойчивыми элементами сказки служат функции действующих лиц, независимо от того, кем и как они выполняются. Они отражают основные составные части сказки» $[9,25]$.

Однако если в фольклорной сказке герой - это функция, то в сказке литературной герой - всегда характер, более или менее разработанный (иногда данный, так сказать, пунктиром), но всегда присутствующий. И главная задача писателя, создающего сказку на основе фольклорной сюжетики и образности (а «Сказка о попе и о работнике его Балде» именно такова), состоит в том, чтобы органично, естественно совместить фольклорную функцию и литературный характер. По мысли В. Непомнящего, А. Пушкин пытался соединить дух фольклора и живой, несказочный характер (пусть и обозначенный не сразу заметным пунктиром). «Это-то и “подвело” его. Оживив попа, превратив сказочный тип, абстрактную схему в реального человека, он в то же время оставил в силе канон - страшный приговор народной сказки попу как типу "хозяина" и получилось неразрешимое противоречие двух мировосприятий, двух творческих методов» [6, 150].

С этим трудно не согласиться. Действительно, поп в народной сказке - не живой человек, а сама жадность, и её уничтожение можно только приветствовать, а у А. Пушкина поп, пусть и жадный, но живой человек, которого не грех и пожалеть.

На этом можно было бы поставить точку, если бы не одно обстоятельство. Характеристика второго уровня смысла сказки приводит к выводу, что в ней существует «неразрешимое противоречие» творческих методов, которое и подводит А. Пушкина (мастерство же поэта оказалось в умении так «замаскировать» противоречие, что обычный читатель, не филолог, и не замечает его). Однако сути дела это не меня- 
ет. Получается, что А. Пушкин не смог полностью решить задачу совмещения фольклорной функции и литературного характера. И если это так, то «Сказка о попе и о работнике его Балде» - просто неудачная сказка. Этому решительно противоречит и наше нравственное чувство, и всенародная известность (и популярность) сказки. Вообще, говорить об А. Пушкине в категориях «не сумел», «не получилось», «не удалось» глубоко ошибочно. Пушкин мог всё.

В чём же дело? Ответ даёт третий план смысла сказки, проступающий (пусть и не всегда отчётливо) за первыми двумя.

Вспомним снова начало сказки:

Жил-был поп,

Толоконный лоб.

Пошел поп по базару

Посмотреть кой-какого товару.

Навстречу ему Балда

Идет, сам не зная куда.

«Что, батька, так рано поднялся?

Чего ты взыскался?»

Поп ему в ответ: «Нужен мне работник:

Повар, конюх и плотник.

А где найти мне такого

Служителя не слишком дорогого?» (351)

В. Непомнящий так комментирует эту сцену: «В результате перед нами вовсе не только “отрицательный” персонаж, однозначно полярный “положительному”. Получился действительно глуповатый, действительно прижимистый, но какой-то уж очень по-русски безоглядный и в чём-то даже трогательный “эксплуататор”. Он сам есть мужик, как и Балда, с той лишь разницей, что у него есть должность; оба они шатаются сейчас без дела и без определённого намерения, оба стремятся одурачить друг друга...» [6 197].

Эту трактовку В. Непомнящего можно оспорить. Во-первых, поп и Балда вовсе не стремятся «одурачить друг друга»: они заключают соглашение, условия которого ими выполняются; во-вторых, поп не есть мужик, такой же, как и Балда: сказать о священнике, что "у него есть должность», значит 
свести его деятельность к чиновничьей; в том-то и дело, что поп - не мужик, он служит (в отличие от мужика) не бытовым, а бытийным силам. Наконец, в-третьих, герои вовсе не «шатаются без дела и без определённого намерения»: поп ищет работника «не слишком дорогого». Обратите внимание: поп помнит, что работник стоит дорого и озабочен он лишь тем, чтобы не было «слишком». Получается, что (по крайней мере, в начальной сцене) поп вовсе не жадный, и его наказывают, следовательно, вообще без вины. За что же? Ответ, пусть «гипотетический», последует чуть позднее.

Что же касается Балды, то он приходит на базар, как можно полагать, тоже не просто так. Пушкинская сказка строится на основе народной бытовой сказки, но причина появления Балды отсылает читателя к сказке волшебной. А волшебно-сказочный мир, вопреки мнению многих фольклористов, это мир без выбора [5]. Поэтому не герой выбирает свою Судьбу-Дорогу, а наоборот, именно Дорога-Судьба выбирает героя (часто Ивана-дурака, то есть почти Балду) и ведёт его. Поэтому «идти куда глаза глядят», «идти, не зная куда» в волшебной сказке означает идти прямо к цели, идти туда, где находится смысл жизни героя, его призвание, место, где герой совершает свой главный сказочный подвиг.

Путь «куда глаза глядят» приводит Балду на базар к попу. Поэтому не случайно Балда заговаривает с попом первым, чтобы обратить на себя его внимание. Поп ему охотно отвечает, и их диалог носит ласково-фамильярный характер, в нём нет и следа социального антагонизма (в этом В. Непомнящий прав), но это и не разговор двух мужиков, не случайно Балда обращается к попу «батька», сразу же выделяя главное.

Итак, в первой сцене на базаре поп сразу же манифестируется как священник и ищет он себе работника особого - повара, конюха и плотника - всех в одном лице. Это выглядит довольно странным, ведь повара и конюха объединяет лишь то, что оба они, как сказал бы М. Бахтин, обслуживают «телесный низ», но кто из нормальных людей желал бы, чтобы у него поваром работал конюх? Какой (и из чего) обед он приготовит: в компании «повара» и «конюха» резко снижа- 
ется и обладающая (в отличие от двух первых) светлыми значениями фигура плотника, точнее, как бы подавляется ими. Возникает некий, пока неясный, инфернальный (во всяком случае не вполне человеческий) оттенок в образе попа.

Получается, что Балда целенаправленно идёт именно к попу (которого в первой сцене трудно обвинить в жадности, но желания которого также трудно назвать человеческими и приличествующими священнику) и делает ему предложение, от которого, говоря современным языком, попу трудно (даже невозможно) отказаться: служить попу «усердно и очень исправно» всего за три щелчка по лбу.

Возникает вопрос: почему Балда согласен потерять целый год, оставить все свои другие дела и занятия, служа попу? Неужели лишь для того, чтобы наказать попа за жадность, которой у него в первой сцене просто-напросто нет? Ведь Балда делает всё от него зависящее, чтобы непременно оказаться у попа в услужении. Более того, он легко и непринуждённо входит в попову семью:

Попадья Балдой не нахвалится,

Поповна о Балде лишь и печалится,

Попёнок зовет его тятей:

Кашу заварит, нянчится с дитятей. (352)

Кого ребёнок считает своим отцом? Почему поповна печалится лишь о Балде?

Жизнь в услужении у попа, к которой так стремился Балда, оказывается необходима, чтобы раскрыть страшную тайну попа. Поп откуда-то (откуда?) знает, что «Щелк щелку ведь рознь» и поэтому панически боится, казалось бы лёгкой и пустяковой расплаты. И Балда, и поп знают нечто, что прямо не сказано в тексте. Поп, по совету попадьи:

Закажи Балде службу, чтоб стало ему невмочь;

И требуй, чтоб он её исполнил точь-в-точь (352), даёт Балде задание, которое обычному человеку (а мы уже убедились, что Балда таким не является) действительно не выполнить:

Слушай: Платить обязались черти.

Мне оброк до самой моей смерти, 
Лучшаго-б не надобно дохода,

Да есть на них недоимки за три года.

Как наешься ты своей полбы,

Собери-ка с чертей оброк мне полный. (353)

Далее следует комическая сцена обмана бесёнка и получения оброка. О комическом, даже балаганном, характере этой сцены говорят многие, пишущие о сказке А. Пушкина, подчёркивая её близость к русскому фольклору, в котором имеется образ смешного, глупого чёрта, мало связанный с христианскими представлениями о нём. Однако у А. Пушкина рядом с комическим соседствует и серьёзное. В фольклористике давно (особенно после работ Д.Н. Медриша) известно, что даже простая цитата из фольклорного текста в литературном произведении всегда меняет свой первоначальный фольклорный смысл. Так и происходит в «Сказке о попе и о работнике его Балде». Комические фольклорные сказочные черты, оставаясь таковыми в пушкинской сказке, обнаруживают свою тоже фольклорную, но уже серьёзную, праоснову. Как отмечал в своё время С. Максимов, одно из излюбленных мест обитания чертей в земном мире - это болото. «Болотные чёрты живут семьями, имеют жён. Плодятся и множатся, сохраняя свой род на бесконечные времена. С их детьми, бойкими и шустрыми чертенятами (хохликами), такими же чёрными (в отличие от немецких красненьких), мохнатыми и в шерсти, с двумя острыми рогами на макушке головы и длинным хвостом, не только встречались деревенские русские люди, но и входили с ними в разнообразные сношения. Образчики и доказательства тому в достаточном количестве разбросаны в народных сказках и, между прочим, в известной всем пушкинской сказке о работнике Балде» $[3,8]$.

Такого рода черти имеют прямое отношение к христианским представлениям (в духе «народного христианства»), они - враги рода человеческого. Именно от таких врагов требует оброк поп. На первый взгляд, кажется, что это («Лучшего б не надобно дохода») лишний раз подтверждает жадность попа. Но так было бы, если на месте попа был бы другой персонаж (какой-нибудь, скажем, купец-остолоп), хотя 
и его связь с чертями не красила бы. Но от чертей требует оброк именно священник. Да, конечно, в древнерусской традиции, в «Киево-Печерском патерике» или в «Путешествии архиепископа Иоанна на бесе в Иерусалим», бесы могут служить святому, но это всегда кратковременный момент защиты в борьбе с бесами и их искушениями. Связь же пушкинского попа с чертями носит длительный («до самой смерти») характер (у них накопились «недоимки за три года») и не имеет отношения к борьбе с бесами. Ведь тот, кто платит оброк («крестьянин») находится в зависимости от хозяина («помещик», «государственная казна»). Выходит, что поп главный у тех, кто платит ему оброк (как «помещик» у «крестьян»). Следовательно, пушкинский поп, гипотетически рассуждая, главный у чертей. Так кто же он есть? Получается, что поп оказывается, по сути дела, предателем священнического долга, дела, которому он должен служить. И вот это - его настоящая вина, именно за это он должен быть наказан. И наказание, при такой интерпретации текста, полностью соответствует преступлению.

Опять-таки, гипотетически рассуждая, получается, что некие высшие (но безусловно христианские) силы посылают Балду «расследовать» преступление попа, раскрыть его тайну, делегировав Балде право судить и наказывать. Не случайно образ Балды по ходу действия укрупняется, как и расширяется место этого действия: «базар» $\rightarrow$ «подворье попа» $\rightarrow$ «море». Последний локус придаёт свершающемуся поистине мировой характер. Так же и с Балдой: за обликом деревенского дурачка проступают черты героя волшебной сказки, а в финальных сценах - даже богатыря:

Старый Бес стал тут думать думу.

А Балда наделал такого шуму,

Что всё море смутилось

И волнами так и расходилось. (356)

Так сделать способен только богатырь.

В финале сказки (последний раз) А. Пушкин, как мы помним, называет попа стариком. Называет потому, что 
поп отринул священничество, стал просто человеком, старым и слабым.

А Балда приговаривал с укоризной:

«Не гонялся бы ты, поп, за дешевизной!» (358)

«Дешевизна» - это не материальные ценности (вернее, не только), это прежде всего то, чем бесы могут соблазнить человека.

За предельно «простым» и «ясным» первым уровнем смысла пушкинской сказки проступают (с разной степенью отчётливости) другие, уже далеко не простые, уровни смысла, в которые, как и в других произведениях поэта, можно углубляться бесконечно.

\section{Примечания}

Статья подготовлена в рамках реализации комплекса мероприятий Программы стратегического развития ПетрГУ на 2012-2016 гг.

1 Злотников Р. Царь Фёдор. Орёл взмывает ввысь. М.: Альфа-Книга, 2010. C. 234.

2 Пушкин А.С. Собрание сочинений: В 8 т. Т. 3. М., 1968. Далее текст сказки цитируется по этому изданию. В скобках арабской цифрой указывается страница.

\section{Список литературы}

1. Азадовский М. Литература и фольклор. Л.: Гослитиздат, 1938. 296 с.

2. Лупанова И. Русская народная сказка в творчестве писателей первой половины XIX века. Петрозаводск: Госиздат Карел. АССР, 1959. $504 \mathrm{c}$.

3. Максимов С. Нечистая, неведомая и крестная сила. СПб.: Полисет, 1994. $443 \mathrm{c}$.

4. Медриш Д. Н. Путешествие в Лукоморье. Сказки Пушкина и народная культура. Волгоград: Перемена, 1992. 144 с.

5. Неёлов Е. М. Сказка. Фантастика. Современность (Глава 4 «Мир без выбора»). Петрозаводск: Карелия, 1987. 124 с.

6 Непомнящий В. Заметки о сказках Пушкина // Вопросы литературы. 1972. № 3. С. $124-151$ c.

7. Непомнящий В. О сказках Пушкина // Детская литература. 1966. № 7. C. $3-10$.

8. Непомнящий В. Поэзия и судьба. М.: Сов. писатель, 1987. 446 с.

9. Пропn В. Я. Морфология сказки. М.: Наука, 1969. 168 с. 
10. Розанов В. Сочинения. М.: Васильевский остров, 1990. 574 с.

11. Сдобнов В. Русская литературная демонология. Тверь: ТверГУ, 2002. $315 \mathrm{c}$.

Evgeniy Mikhaylovich Neyolov

Doctor of Philology, Professor of Petrozavodsk State University

(Petrozavodsk, Russian Federation)

\title{
THE TALE OF THE PRIEST AND OF HIS WORKMAN BALDA BY A. PUSHKIN
}

\begin{abstract}
The Tale of the Priest and his Worker Balda seems the most simple of all the Pushkin's fairy tales. However, this is a very specific simplicity, which can be called 'the simplicity of complexity'. The story contains different levels, which are not apparent immediately. Traditionally, The Tale of Balda has been interpreted as an acute socio-political satire; another approach refers to the peculiarities of folk tales poetics and its literary transformation, determined by the difficulties of combining the folk fairy-tale function of the character with the nature of a literary tale hero. Both of these approaches raise a number of questioins, the main of which is why the Priest was punished, after all. The third interpretation, which is presented in the second part of the article and considers Pushkin's fairy tale in the Christian context, allows us to reveal the deeper connotations of Pushkin's intention, giving the opportunity to comment differently some parts of the text, usually overlooked by researchers that are focused only on a "superficial layer" of the meaning of the text.
\end{abstract}

Keywords: Folk tale, a literary tale, the priest, the Balda, the devil

\section{References}

1. Azadovskiy M. Literatura i fol'klor [Literature and folklore]. Leningrad, Goslitizdat Publ., 1938. 296 p.

2. Lupanova I. Russkaya narodnaya skazka $v$ tvorchestve pisateley pervoy poloviny XIX veka [Russian folk tale in the works of the writers of the first half of the 19th century]. Petrozavodsk, Karelo-Finnish SSR Publ., 1959. $504 \mathrm{p}$.

3. Maksimov S. Nechistaya, nevedomaya i krestnaya sila [Evil, unknown and godmother power]. Saint-Petersburg, Poliset Publ., 1994. 443 p.

4. Medrish D.N. Puteshestvie v Lukomor'e. Skazki Pushkina i narodnaya kul'tura [Journey to Lukomorye. Pushkin's fairy tales and national culture]. Volgograd, Peremena Publ., 1992. 144 p.

5. Neyolov E. M. Skazka. Fantastika. Sovremennost' (Glava 4 «Mir bez vybora») [Tale. Science Fiction. Modernness (Chapter 4 «A World without choice»)]. Petrozavodsk, Karelia Publ., 1987. 124 p. 
Е. М. Неёлов

6. Nepomnyashchiy V. Zametki o skazkakh Pushkina [Notes about Pushkin's fairy tales]. Voprosy literatury [Questions of Literature], 1972, no. 3, pp. 124-151.

7. Nepomnyashchiy V. O skazkakh Pushkina [About tales of Pushkin]. Detskaya literatura [Children's literature]. 1966. no. 7, pp. 3-10.

8. Nepomnyashchiy V. Poeziya i sud'ba [Poetry and destiny]. Moscow, Sovetskiy pisatel' Publ., 1987. 446 p.

9. Propp V. Ya. Morfologiya skazki [The Morphology of the fairy tale]. Moscow, Nauka Publ., 1969. 168 p

10. Rozanov V. Sochineniya [Works]. Moscow, Vasil'evskiy ostrov Publ., 1990. $574 \mathrm{p}$.

11. Sdobnov V. Russkaya literaturnaya demonologiya [Russian literary demonology]. Tver, TverSU Publ., 2002. 315 p. 